\title{
Understanding Care Integration from the Ground Up: Five Organizing Constructs that Shape Integrated Practices
}

\author{
Deborah J. Cohen, PhD, Bijal A. Balasubramanian, MBBS, PhD, \\ Melinda Davis, PhD, Jennifer Hall, MPH, Rose Gunn, MA, Kurt C. Stange, MD, PhD, \\ Larry A. Green, MD, William L. Miller, MD, MA, Benjamin F. Crabtree, PhD, \\ Mary Jane England, MD, Khaya Clark, PhD, and Benjamin F. Miller, PsyD
}

Purpose: To provide empirical evidence on key organizing constructs shaping practical, real-world integration of behavior health and primary care to comprehensively address patients' medical, emotional, and behavioral health needs.

Methods: In a comparative case study using an immersion-crystallization approach, a multidisciplinary team analyzed data from observations of practice operations, interviews, and surveys of practice members, and implementation diaries. Practices were drawn from 2 studies of practices attempting to integrate behavioral health and primary care: Advancing Care Together, a demonstration project of 11 practices located in Colorado, and the Integration Workforce Study, a study of 8 practices across the United States.

Results: We identified 5 key organizing constructs influencing integration of primary care and behavioral health: 1) Integration REACH (the extent to which the integration program was delivered to the identified target population), 2) establishment of continuum of care pathways addressing the location of care across the range of patient's severity of illness, 3 ) approach to patient transitions: referrals or warm handoffs, 4) location of the integration workforce, and 5) participants' mental model for integration. These constructs intertwine within an organization's historic and social context to produce locally adapted approaches to integrating care. Contextual factors, particularly practice type, influenced whether specialty mental health and substance use services were colocated within an organization.

Conclusion: Interaction among 5 organizing constructs and practice context produces diverse expressions of integrated care. These constructs provide a framework for understanding how primary care and behavioral health services can be integrated in routine practice. ( $\mathrm{J}$ Am Board Fam Med 2015;28: S7-S20.)

Keywords: Delivery of Health Care, Integrated; Practice-based Research, Primary Health Care

In 2006, the Institute of Medicine and National Academy of Sciences issued a report in the Quality Chasm Series on Mental Health and Substance Use

This article was externally peer reviewed.

Submitted 6 February 2015; revised 8 May 2015; accepted 22 May 2015.

From the Departments of Family Medicine and of Medical Informatics and Clinical Epidemiology, Oregon Health \& Science University, Portland (DJC); Department of Epidemiology, Human Genetics, and Environmental Sciences, University of Texas Health Science Center, Houston School of Public Health (BAB); Harold Simmons Comprehensive Cancer Center, UT Southwestern Medical Center, Dallas, TX (BAB); Oregon, Rural Practice-Based Research Network (MD); Department of Family Medicine, Oregon Health \& Science University, Portland (MD, JH, RG, KC); Department of Epidemiology \& Biostatistics, Sociology and
Disorders. ${ }^{1}$ The recommendation was clear: to achieve quality health care, mental health and substance use disorders must be integrated into health

the Case Comprehensive Cancer Center, and Clinical and Translational Science Collaborative, Case Western Reserve University, Cleveland, OH (KCS); Department of Family Medicine, University of Colorado School of Medicine, Aurora (LAG, BFM); Department of Family Medicine, Lehigh Valley Health Network, Allentown, PA (WLM); Department of Family Medicine and Community Health, RutgersRobert Wood, Johnson Medical School, Somerset, NJ (BFC); Department of Health Policy and Management, Boston University School of Public, Health, Boston, MA (MJE)

Funding: This work is funded by grants from The Colorado Health Foundation, the Agency for Healthcare Research and Quality (8846.01-S01), the CalMHSA Foundation (AWD-131237), and Maine Health Access Foundation 
care. In 2008, the U.S. Congress passed parity legislation ensuring that mental health and substance use disorders were covered the same as other medical conditions. ${ }^{2}$ With the passage of the Affordable Care Act, additional systems were put in place to help achieve this goal. ${ }^{3}$

In addition to policy changes, there is strong evidence that patient experience and outcomes improve and costs are contained when behavioral and medical problems are addressed together. ${ }^{4-8} \mathrm{How}_{-}$ ever, integration has not been consistently adopted in health care systems across the country. ${ }^{9} \mathrm{Al}-$ though the research has been robust around the benefits of integration, the vast majority of it has been disease specific or focused on select populations. ${ }^{10,11}$ In primary care settings, patients often present with multiple chronic conditions and have behavioral health needs that may far exceed a particular disease. ${ }^{12}$ To this end, 1 of the most important remaining problems is how to integrate primary care and behavioral health within the current fragmented health system and with primary care practices that are constantly being asked to change. ${ }^{1,13,14}$ We use the term integration approach to refer to the constellation of elements that shape how practices organize and deliver integrated care. An integration approach brings together the structures and processes that make integration possible.

This study was undertaken to understand how a diverse sample of practices integrate behavioral health care and primary care. In a comparison we attempted to elucidate the organizing constructs and constellation of factors that influence realworld practices' attempts to integrate care.

\section{Methods \\ Sample}

We studied 19 practices located in the United States, and purposefully sampled for their diversity

(2012FI-0009). KCS's time is supported as a Scholar of The Institute for Integrative Health, and by a Clinical Research Professorship from the American Cancer Society. MD's time is supported by an Agency for Healthcare Research and Quality-funded PCOR K12 award (Award No. 1 K12 HS022981 01).

Conflict of interest: none declared.

Corresponding author: Deborah Cohen, $\mathrm{PhD}$, Oregon Health \& Science University, School of Medicine, Mail Code: FM, 3181 SW Sam Jackson Park Road, Portland, OR 97239-3098 (E-mail: cohendj@ohsu.edu). and efforts to integrate behavioral health and primary care.

Eleven practices participated in the Advancing Care Together (ACT) program funded by The Colorado Health Foundation. A Steering Committee of local and national leaders in integration selected practices applying to participate in a study of their attempts at integration. ACT practices varied in their experience with integrated care, but most were integrating behavioral health and primary care for the first time.

Eight practices participated in the Integration Workforce Study (IWS) to identify workforce needs for integrated care. This work was funded by the Agency for Health care Research and Quality (AHRQ), with supplemental funding from the CalMHSA Foundation and Maine Health Access Foundation. For this study, an Expert Panel composed of national leaders in integration identified practices known to be integrating care. We used this information to identify practices with variation in organizational structure and geographic location, and conducted interviews with select leaders at each organization to identify practices with the strongest integration programs in each region. None of the study practices were directed to implement any particular integration intervention, strategy, or approach.

\section{Study Design}

ACT was a longitudinal study designed to observe practices as they implemented their programs over a 3-year study period (September 1, 2011 to August $31,2014)$. IWS was a cross-sectional study, and we conducted 1 data collection site visit at each practice between December 2012 and October 2013. The same team of researchers worked on both studies.

\section{Data Collection}

Details regarding data collection for ACT and IWS are reported elsewhere. ${ }^{15,16}$ Table 1 provides additional details about data collection process for this study. Online diary data were collected among ACT practices only because this data collection method was designed to understand and prospectively collect implementation experiences. We also assessed implementation REACH; defined as the proportion of patients in the intended target population that received integration. ${ }^{17}$ Because it was 
Table 1. Study Data Sources and Measures and Data Collection Processes

\begin{tabular}{|c|c|c|c|}
\hline Primary Data Type & Description of Data & Data Collection Process & Study \\
\hline Documents & $\begin{array}{l}\text { Grant applications and reports to } \\
\text { TCHF (ACT only), e-mail } \\
\text { communications, innovator } \\
\text { presentations, and documents } \\
\text { from innovators (scheduling } \\
\text { templates, educational } \\
\text { materials). }\end{array}$ & $\begin{array}{l}\text { For ACT, documents were collected throughout the } \\
\text { study period and during observation visits. The } \\
\text { Program Office and grantees share documents } \\
\text { freely. For IWS, we collected relevant care } \\
\text { delivery documents during site visits. }\end{array}$ & ACT IWS \\
\hline Online diaries & $\begin{array}{l}\text { Members from each ACT } \\
\text { innovation team (practice) } \\
\text { report on implementation } \\
\text { experiences via an online } \\
\text { journal that is shared with } \\
\text { other members of their team } \\
\text { and the evaluation team. }\end{array}$ & $\begin{array}{l}\text { Evaluation team identified } 5 \text { to } 7 \text { people in each } \\
\text { ACT practice to post diary entries. Each team } \\
\text { had a private online diary room. Diary keepers } \\
\text { were asked to post every } 2 \mathrm{wk} \text {. Evaluators } \\
\text { interacted with diary keepers to encourage } \\
\text { posting. }\end{array}$ & $\mathrm{ACT}$ \\
\hline Field observation & $\begin{array}{l}\text { Two 4-day visits with each } \\
\text { practice to observe care } \\
\text { delivery }\end{array}$ & $\begin{array}{l}\text { During visits, } 2 \text { to } 5 \text { evaluators observed the care } \\
\text { delivery process by shadowing clinicians, clinical } \\
\text { support staff, and non-clinical support staff. This } \\
\text { included observing huddles and other team } \\
\text { meetings. During field observation, researchers } \\
\text { took brief notes or jottings and used these to } \\
\text { create a detailed set of field notes. }\end{array}$ & ACT IWS \\
\hline Interviews & $\begin{array}{l}\text { Semi-structured interviews were } \\
\text { conducted with practice } \\
\text { members }\end{array}$ & $\begin{array}{l}\text { We conducted semi-structured interviews with } 2 \text { to } \\
17 \text { practice members during field visits, } \\
\text { depending on practice size. Practice member with } \\
\text { on-the-ground knowledge of practice operations } \\
\text { and relevant contextual knowledge were selected } \\
\text { for interviews. }\end{array}$ & ACT IWS \\
\hline Survey & $\begin{array}{l}\text { Completed by each practice to } \\
\text { collect information about the } \\
\text { organization (e.g., ownership, } \\
\text { staffing patterns, turnover, } \\
\text { panel characteristics) }\end{array}$ & $\begin{array}{l}\text { We distributed surveys to one person at each } \\
\text { practice who worked with members of the } \\
\text { practice to complete it. Information was returned } \\
\text { to us either online or via paper. Survey responses } \\
\text { were clarified with practices as needed. }\end{array}$ & ACT IWS \\
\hline REACH & $\begin{array}{l}\text { Either an exact count or an } \\
\text { estimate of the proportion of } \\
\text { patients in the practice who } \\
\text { received some level of } \\
\text { integrated care }\end{array}$ & $\begin{array}{l}\text { For ACT we developed and tailored a tracking } \\
\text { sheet to collect REACH data. Practices collected } \\
\text { these data for one year and shared data with us } \\
\text { quarterly. We reviewed data with practice to } \\
\text { determine accuracy and made corrections as } \\
\text { needed. For IWS practices, the research team } \\
\text { used observational to estimate REACH for each } \\
\text { practice. }\end{array}$ & ACT \\
\hline
\end{tabular}

ACT, Advancing Care Together; IWS, Integration Workforce Study; TCHF, The Colorado Health Foundation.

not feasible to directly assess REACH with patientlevel data among IWS sites, we used qualitative data from practice observation to assess REACH in both ACT and IWS practices. We defined the practice's target population as all the patients in the practice. For primary care practices, we defined "broad reach" as evidence of consistent involvement of behavioral health clinicians (BHCs) in a broad range of primary care services (eg, depression, anxiety, diabetes, blood pressure management), and "limited reach" as consistent evidence that BHCs were involved in patient care for only a fraction of the practice population. For Community Mental Health Centers (CMHCs) these definitions were the same, but applied to the primary care clinicians (PCCs).

\section{Data Management}

Practice survey data were transferred to Excel and entered into SPSS for data analysis. Interviews were audio recorded and professionally transcribed then reviewed for accuracy and deidentified. Qualitative data were put into Atlas.ti (Version 7.0, Atlas.ti Scientific Software Development GmbH, Berlin, Germany) a program for qualitative data management and analysis. Institutional Review Boards at Oregon Health \& Science University and the University of Colorado-Denver approved this study.

\section{Analysis}

We used a grounded theory approach to analyze data, informed by the work of Miller and 
Table 2. Organizing Principles: Conceptual and Operational Definitions

\begin{tabular}{|c|c|c|}
\hline Organizing Principles & Conceptual Definition & Operational Definition \\
\hline Integration REACH & $\begin{array}{l}\text { Extent to which integrated services are } \\
\text { available to practice population }\end{array}$ & $\begin{array}{l}\text { Strategy for identifying patient need (systematic, } \\
\text { clinical discretion). Access to integrated care } \\
\text { (limited, broad) }\end{array}$ \\
\hline Location of integration workforce & $\begin{array}{l}\text { Proximity of the professionals on the } \\
\text { integrated care team }\end{array}$ & $\begin{array}{l}\text { Primary care and behavioral health colocated; } \\
\text { Psychiatrist co-located; PCCs and BHCs } \\
\text { located in same team workspace }\end{array}$ \\
\hline Approach to patient transitions & $\begin{array}{l}\text { Strategies that practice employs when } \\
\text { introducing and engaging patients } \\
\text { with another professional on the } \\
\text { care team }\end{array}$ & Warm-handoffs and referrals \\
\hline Establish care pathways & $\begin{array}{l}\text { Determining the level and type of care } \\
\text { practice can provide, including care } \\
\text { requiring referral to outside } \\
\text { resources. Establish paths for both. }\end{array}$ & $\begin{array}{l}\text { Care paths for patients with more serious illness } \\
\text { (emotional and behavioral) are identified (yes/ } \\
\text { no) }\end{array}$ \\
\hline Shared mental model & $\begin{array}{l}\text { Practice members have shared } \\
\text { understanding of practice model for } \\
\text { integration }\end{array}$ & $\begin{array}{l}\text { The majority of practice members talk about } \\
\text { and behave in ways that reinforce the same } \\
\text { model for integration (yes/no) }\end{array}$ \\
\hline
\end{tabular}

Crabtree ${ }^{18}$ and Borkan. ${ }^{19}$ A multidisciplinary team read and discussed data, as they were collected, tagging important sections of text, and naming them (eg, screening, brief counseling) so text could be retrieved, clustered, and further analyzed. When we reanalyzed the data, we identified a small number of crosscutting organizing constructs that distinguished integration approaches. We identified as many nonduplicative discrete constructs as possible, established conceptual and operational definitions for each construct, and used both qualitative and quantitative data to categorize practices on constructs. Where there was uncertainty, we went back to the data or to a practice participant to clarify interpretations. Through this iterative process, we reached thematic saturation, as no new organizing constructs emerged through data analysis. We then developed a matrix characterizing practices by organizing constructs, and along with other qualitative data, used this to identify and understand interconnections among organizing constructs and the implications for delivery of integrated care.

\section{Results}

We identified 5 key organizing constructs that influenced real-world integration approaches observed in practices across the United States:

1. Integration REACH

2. Establishment of continuum of care pathways

3. Approach to patient transitions

4. Location of the integration workforce

5. Shared integration mental model.
We call these organizing constructs because they were central to the integration efforts we observed in real-world practices, and variation in these constructs allowed us to discriminate among practices with regard to integration. Table 2 includes conceptual and operational definitions of the organizing constructs.

Characteristics of the 19 practices we studied are presented in Table 3. Twelve were primary care practices representing a range of practice types and ownership; the others were mental health care practices.

Table 4 provides a description of the integration approach at each practice. Below, we describe salient aspects of each organizing construct observed across practices and exemplify how constructs intertwine with each other and with contextual factors, such as practice type, to influence practices' integration efforts.

\section{Integration Reach}

Integrated care is comprehensive care of patients' medical, emotional, and behavioral health needs, and aims to reach a large segment of patients served by a practice through, for example, systematically implementing approaches to identify patient need (eg, annual screening). ${ }^{20}$ Within our sample, practices fell into two categories: those with integrated programs that strived to reach a broad population of practice patients, and others that focused on reaching a smaller population of patients, often patients experiencing acute crises and/or specific conditions such as depression or substance use alone. Practices that developed system-level routines (eg, patient screening 


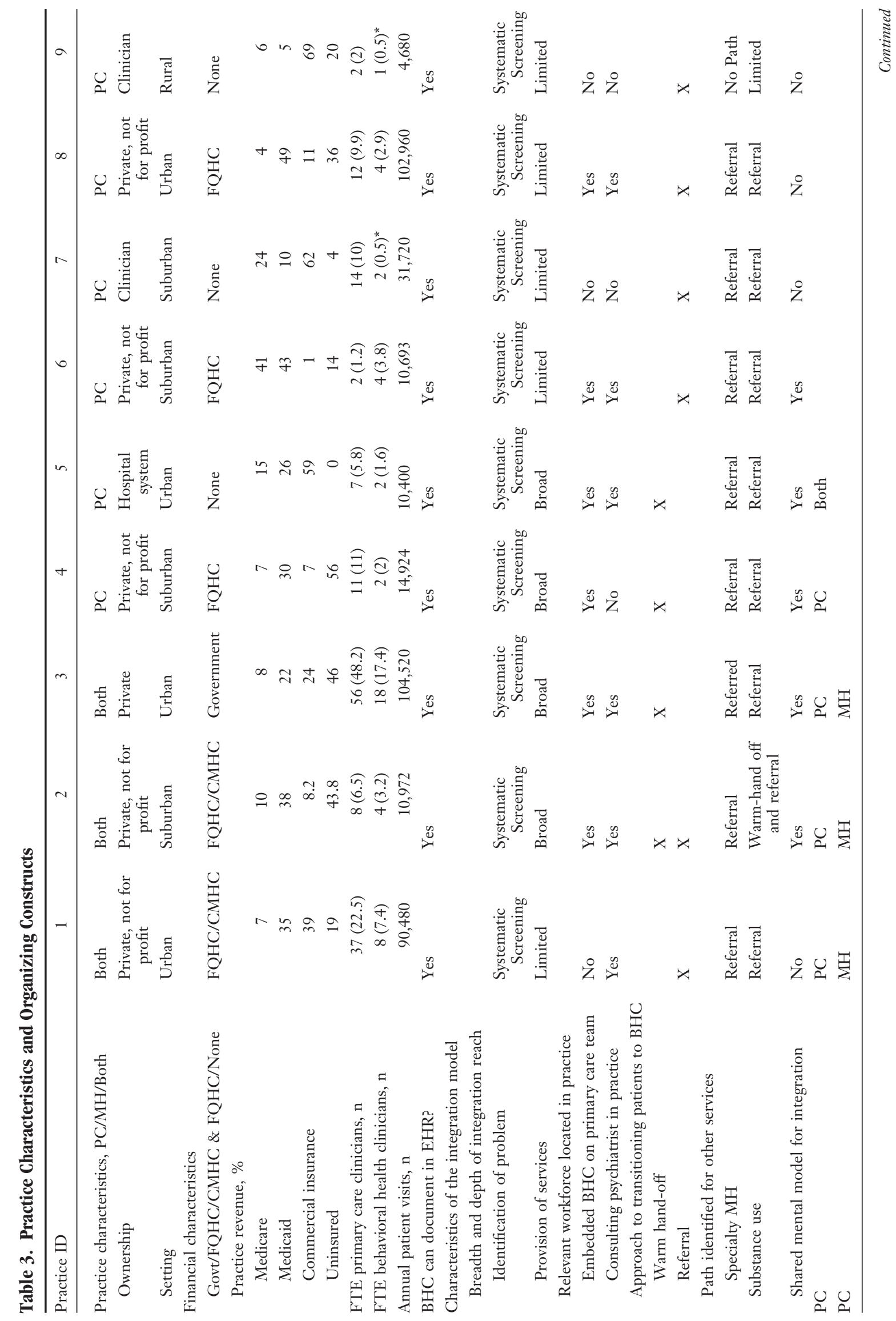




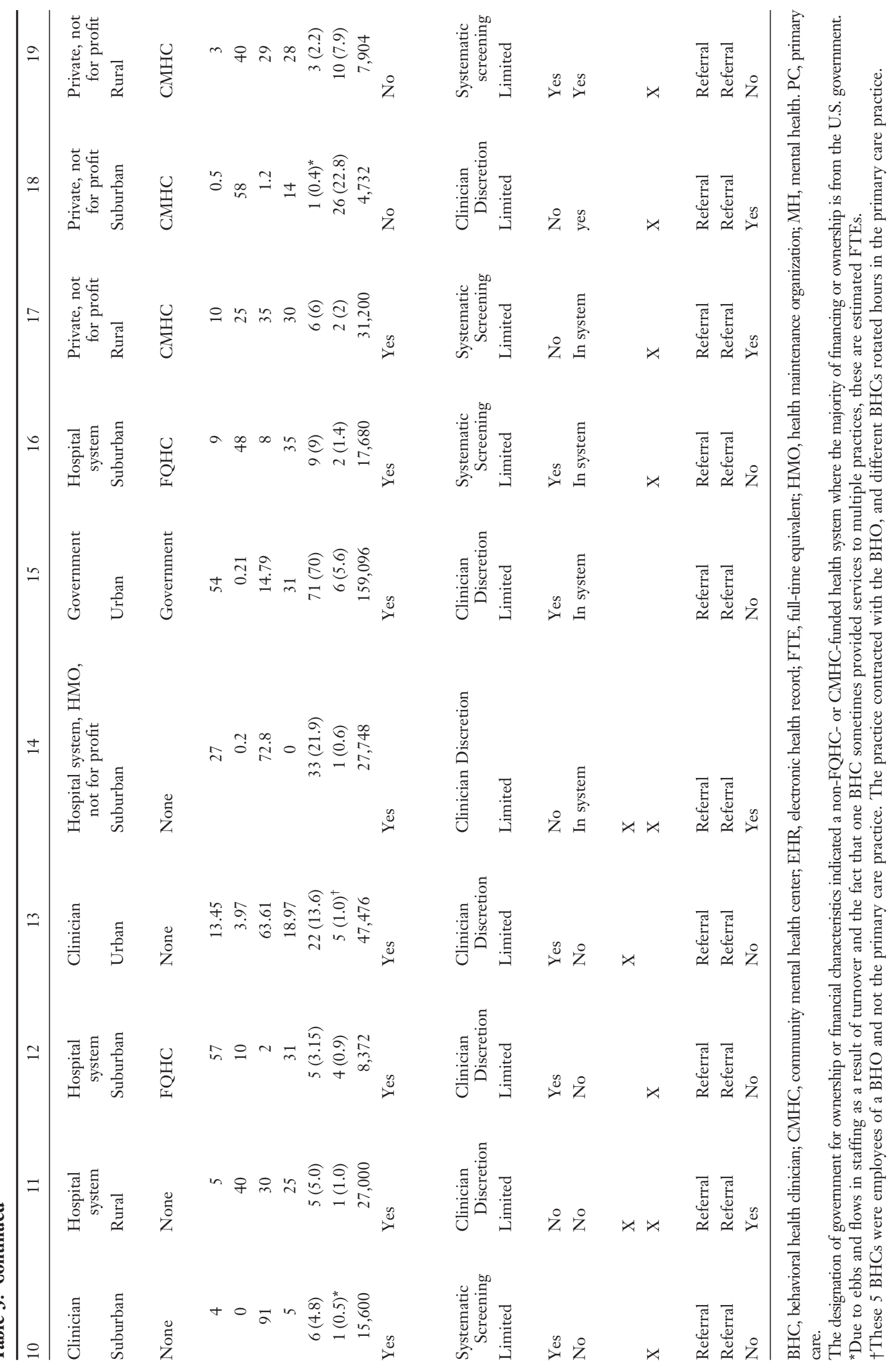


Table 4. A Description of Practices' Integration Approaches $(n=19)$

Practice ID Integration Approach

FQHC/CMHC within one organization. CMHC employs multiple traditional BHCs including psychiatrists. One $\mathrm{BHC}$ serves as a care coordinator/care manager and does the majority of $\mathrm{BH}$ intake assessments. BHCs are located on a different floor and isolated from PC teams. In PC, MAs systematically screen for BH needs (PHQ-2/ PHQ-9), referring PC patients to BHCs as needed. BHCs provide traditional therapy; psychiatrists handle medication management. Care manager gets involved with primary care when there is a crisis and immediate access to services (same day) is needed. Refer out for SU counseling; care manager handles this referral.

FQHC/CMHC within one organization. Practice employs BHCs and has post-doctoral training program in psychology, but trainees do not provide majority of $\mathrm{BH}$ care for patients. One $\mathrm{BHC}$ is assigned to two $\mathrm{PC}$ teams, although BHCs assist other PC teams as needed. Patients systematically screened for BH needs by MA. As needs are identified, BHCs approached for warm hand-off. During hand-offs, BHCs rapidly assess patients' needs, conferring with the patient and PC team about diagnosis and treatment options. BHCs provide brief (30 min) problem-focused therapy to patients, and refer patients with SPMI to CMHC on the third floor. Consulting psychiatrist moves across PC teams and is responsible and available for consultation and assistance with medication management. BHCs conduct several group therapy sessions for patients, including for SU.

PC practice in integrated health system that includes a full spectrum of $\mathrm{PC}$ and $\mathrm{BH}$ services, including specialty services. Practice has hired BHCs to work with the PC teams. Patients are systematically screened for BH needs by MAs and BHCs; BHCs scrub the chart daily to identify patients coming in who might benefit from a brief checkin from the BHC. PCCs engage BHC as needed via warm handoff. BHCs rapidly assess patients' need, determine whether the patient will benefit from brief, problem-focused therapy, and provide that therapy if needed. For patients who require longer-term services, the BHCs refer the patient to the specialty $\mathrm{MH}$ services within the organization, including SU, and assist with the transition. The wait for these services can be long, and the BHC might provide a therapy bridge until the patient gets into specialty MH. BHCs do some therapy groups. PC practice with post-doctoral training program in psychology that is the main source of BH care. Staff psychologists supervise students and provide direct care. BHCs are located throughout the building, often in close proximity to the PC teams. Initially, BHCs scrubbed charts to identify patients on the schedule whom they had not yet met, or who had a pre-existing BH need, dropping in to meet, screen, and check in on the wellbeing of these patients. Now MAs systematically screen patients. When a problem is identified, BHCs do a warm handoff, meet with the patient, and offer brief, problem-focused therapy as needed. Patients with SPMI and SU needs are referred out to a local CMHC. BHCs help with this transition.

$5 \quad$ PC practice that is part of a larger health system that focuses on caring for the most complex patients. The practice employs BHCs and 2 consulting psychiatrists. BHCs work closely with PC teams, taking warm hand-offs and scrubbing the chart to identify patients on the schedule who would benefit from a brief BHC visit. BHCs offer brief, problem-focused therapy. Psychiatrists are available for consults and for medication management. Patients with SU problems and SPMI are referred to other programs in the system. BHCs and other team members help with these transitions.

PC practice that serves a homeless population. Employs three BHCs. MAs systematically screen for BH needs (PHQ-2/PHQ-9). BHCs have isolated offices and conduct traditional therapy appointments. Onsite psychiatrist and psychiatric NP handle medication management. Warm-handoffs to the BHCs are rare as BHCs are fully scheduled. Patients with SPMI are seen in the clinic. Group therapy sessions are offered and often led by a BHC and PCCs. Practice has a therapy group called Safety Seeking for SU and PTSD.

PC practice affiliated with multiple PC practices in the region. BHC is hired to serve patients seen in these practices. BHC is colocated in some practices but not others. Practice does systematic screening to identify $\mathrm{BH}$ needs by having front desk give patients a web tablet. PCCs determine when more in-depth psychological assessment is needed. Staff conduct these assessments, the BHC reviews it, meets with the patients to formulate a diagnosis, and works with the PCC and patient to develop treatment plan, which may be carried out by the PCCs or BHC. BHC does traditional therapy. Patients in need of longer MH services and SU services are referred out. PC practice with two BHCs serving multiple PC teams. MAs screen adult patients. BHCs are located in close proximity to PC teams but are backlogged and typically unavailable for warm handoffs. When a warm handoff occurs, patient can wait several weeks for a BHC appointment. This is because demand may exceed what BHCs can provide, and because BHCs are engaging in traditional therapy.

Small PC practice working with a local, private, not-for-profit mental health center to embed a BHC. The BHC is part time, working 1 to 2 days a week in the practice. BHC works in close proximity to the PC team. The front desk systematically screens for a range of $\mathrm{BH}$ needs. When the screen is positive, the MA flags this for PCCs who then talk to the patient and decide whether the BHC is needed. BHC sees patients in an examination room. BHC schedule is full, making BHC unavailable for warm handoffs or new patients. PCC is aware of this, and may handle some brief counseling him/herself. Practice has limited access and weak relationships with community resources for referral of patients in need of SU or SPMI care.

10 Small PC practice working with local CMHC to embed BHC in the clinic. BHC began part time and expanded to full time. Front desk systematically screens for BH needs. BHC is backlogged and often unavailable for warm handoffs. This may be due to greater need for $\mathrm{BH}$ services than $\mathrm{BHC}$ can manage and $\mathrm{BHC}$ is doing more traditional therapy. BHC handles referrals to the $\mathrm{CMHC}$ and other providers for those patients who need longerterm MH services including SU services. This is an effective process for patients with Medicaid. However, CMHC does not have contracts for commercially insured patients, making securing care for these patients challenging. 


\begin{tabular}{ll}
\hline Practice ID & Integration Approach \\
\hline
\end{tabular}

Rural PC practice. Through an arrangement with local CMHC, this practice has one embedded BHC. Clinical discretion used to identify BH needs. BHCs are backlogged and often unavailable to PCCs for warm handoffs, as BHCs are doing traditional therapy and have full schedules. Because BHCs are from a CMHC there is a clear pathway for patients with SPMI and in need of SU counseling. BHCs handle these referrals.

PC practice with psychology postdoctoral training program, which is the main source of BHC for practice. PCCs use clinical discretion to identify patients with $\mathrm{BH}$ needs. BHC interns are often unavailable to PCCs as they are not located in close proximity to PCC and they have full schedules. Thus, few warm handoffs are made. BHC interns work part time at the practice and see patients based on a referral model for traditionally scheduled therapy appointments. High-needs $\mathrm{MH}$ patients are referred out.

$\mathrm{PC}$ practice with embedded BHCs through an arrangement with a partnering private $\mathrm{BH}$ organization. Through a combination of screening during well visits, clinician discretion and $\mathrm{BHC}$ outreach to $\mathrm{PC}$ teams patients are identified who might benefit from BH services. BHC does warm handoffs and a rapid assessment of patients needs, determining whether patients will benefit from 4 to 6 sessions of brief, problem-focused therapy or if the patient has longer-term needs. BHC provides brief therapy, as needed, or refers (walks) patients in need of longterm therapy to the $\mathrm{BH}$ organization, which is located in the same building. Patients with SU needs are referred out to other organizations as are patients with SPMI on Medicaid or Medicare because of reimbursement challenges.

PC practice is part of integrated health system that includes a full spectrum of PC and MH services including specialty services. System has hired BHCs to work with PC teams. PCCs use their discretion to identify patients in need of BHC services and refer patients to the BHC using the EHR. Warm-handoffs are rare. BHCs are connected to a PC team but may not be in the same location (separated by halls or floors). BHCs do group therapy sessions, provide brief, problem-focused therapy, and help patients who need specialty MH services make that transition either to internal resources or a local CMHC (Medicaid only).

PC practice in integrated health system that includes a full spectrum of PC and BH services, including specialty services. System has hired BHCs to work with PC teams. PCCs use clinical discretion to identify patients who might benefit from $\mathrm{BHC}$ services; they will either refer patients to the $\mathrm{BHC}$ or arrange for a warm handoff. $\mathrm{BHCs}$ are connected to a PC team but may not be in the same location (separated by halls or floors). Distance limits warm handoffs. BHCs do group therapy sessions, provide brief, problem-focused therapy, and help patients who need specialty $\mathrm{MH}$ services make that transition.

PC practice in integrated health system. PC practice has an embedded BHC to work with the PC teams to do brief, problem-focused therapy. Need for BHCs exceeded FTEs available, and program was expanded to include students who help with access. Onsite SU provider added during intervention. BHCs available for warm handoffs and offer brief, problem-focused therapy to patients. Patients who need longer-term therapy and SU services are referred to another clinic in the system.

CMHC hired PA and MA team to serve its patients, and to expand its services to a non-SPMI population. The practice systematically screens its patients to identify physical and behavioral health needs. SPMI patients come to PA by referral from therapist, case managers, or self. Therapists ask patients, including those with SPMI, whether they have a PCC provider. Those without a PCC are offered help in getting them connected with one. The PA, health navigator, or health coach treats patients seeing $\mathrm{PC}$ team who are identified with mild to moderate $\mathrm{BH}$ needs. Therapists in the clinic treat patients with SPMI and SU needs. PA has $>15 \mathrm{y}$ practicing in the community and has connections with medical specialty care providers.

CMHC serving people with SPMI. MH clinicians use their discretion to identify patients who need PCCs and refer these patients to a Care Coordinator. The Care Coordinator assists referred patients with paper work, which must be done prior to the PCC visit. Once completed, Care Coordinator schedules appointment with PCC. PC team is composed of a PA, MA, Care Coordinator, and SU counselor. The PA and MA are on contract with a local FQHC, the SU counselor is on contract with a local SU rehabilitation organization. PC team travels together across $3 \mathrm{CMHC}$ sites. PC team handles the majority of physical health needs as well as likely some mild to moderate $\mathrm{BH}$ needs, and refers patients to medical specialists in the community as needed. Because PA works for an FQHC, specialists are easily identified.

CMHC hired PCC, MA, and front desk team to serve its patients, and expanded services to a non-SPMI population. Practice systematically screens patients using web tablet distributed at front desk to identify physical and $\mathrm{BH}$ needs. In addition to the $\mathrm{BHCs}$ providing traditional therapy, $1 \mathrm{BHC}$ is embedded on $\mathrm{PC}$ team to provide integrated care. Patients with SPMI and SU needs are seen in this practice through individual and group therapy. PC team handles majority of patients' physical health needs but refers out to specialists in the community as needed.

Abbreviations: $\mathrm{BH}$, behavioral health; BHC, behavioral health clinician; CMHC, community mental health center; EHR, electronic health record; FQHC, federally qualified health center; FTE, full-time equivalent; MA, medical assistant; MH, mental health; NP, nurse practitioner; PA, physician assistant; PC, primary care; PCC, primary care clinician; PHQ2/PHQ9, screening tools for depression; SPMI, serious and persistent mental illness; SU, substance use.

during check-in) consistently identified patients most likely to benefit from integration. Practices relying on clinician discretion generally provided services to a more limited range of patients presenting with severe or acute need (see Table 2). Additional evidence supporting the connection between systematic screening and higher REACH was shown among practices participating in ACT. ${ }^{21}$ 
Practices choosing to systematically screen patients wanted: 1) routinized, reliable processes for identifying need; 2) to understand the needs of the population they served; and 3) data to develop and refine their integration approach. Practices relying on clinical discretion did so because of: 1) uncertainty about the sustainability of the integrated approach, 2) a perceived lack of capacity to address population need should systematic screening be employed, 3) a focus on careful resource management; and 4) inertia (the ease of doing things as they have always been done).

\section{Establishment of Continuum of Care Pathways for Patients}

Practices were challenged to determine the level of patient need that could be addressed within the practice, and to recognize patients whose care was best left to others, often outside of the practice. Practices fell into three categories based on how they organized care for integration across the range of patients' severity of illness: 1) practices providing care for patients with mild to moderate illness in the practice, and referring specialty and long-term care needs out to other organizations; 2) practices providing care for mild to moderate illness in the practice, and referring patients to specialty resources in house either in the practice, or within the system; and 3) practices that cared for patients with mild to moderate and more severe illness in the practice, in part because they did not have strong ties with external organizations for referral.

In addition, PCCs and BHCs sometimes consulted with psychiatrists to support patient care, even for patients with mild to moderate needs, particularly when help was needed with diagnoses or medication management. ${ }^{22}$ Access to a consulting psychiatrist could help keep the care of moderate to higher-need patients in the practice. Table 3 shows the majority of federally qualified health centers (FQHCs), FQHC-CMHCs, CMHC, and health system, government and hospital-owned practices were able to establish access to a consulting psychiatrist, and most privately owned primary care practices were not.

\section{Approach to Care Transitions: Referrals and Warm Handoffs}

When organizing care for patients with more specialized, long-term needs, practices needed access to specialty mental health and substance use ser- vices (see Table 3). The majority of independent primary care practices, regardless of size, established relationships with organizations providing these services, but did not have colocated access to specialty mental health. In contrast, FQHC$\mathrm{CMHC}$ hybrid organizations, as well as hospital and government-owned practices, had colocated services for specialty mental health, with clinicians located in other buildings on the same campus, or in another part of the same building. Being in the same system could have advantages for tracking patient engagement in services, information sharing, and followup, as clinicians in these systems had a single shared medical record, although systems did not always take advantage of this level of interconnectivity. In addition, in crisis situations, specialty services could be rapidly engaged. Referral was the method used by practices for engaging patients in specialty services, regardless of service location. A referral is when a patient is directed to make an appointment with another professional (patients may or may not receive scheduling assistance).

When organizing care for patients experiencing mild to moderate problems (eg, mild to moderate depression or anxiety; common acute illnesses, mild to moderate chronic disease), practices colocated needed professionals (ie, BHC in primary care practice; PCC in community mental health) to help patients address these needs. When another health care professional was engaged in the care of patients with mild to moderate needs, this transition occurred either through referral or warm handoff. A warm handoff is when a clinician directly introduces a patient to another clinician at the time of the patient's visit, and often a brief encounter between the patient and the health care professional occurs. ${ }^{23-25}$ When organizing care for patients with mild to moderate problems, 6 practices used warm handoffs.

\section{Location of Integration Workforce and Shared Mental Model}

Table 5 shows a subset of practices employing multiple, full-time PCCs and BHCs with relatively robust financing models for their integration efforts (eg, FQHC, FQHQ-CMHC, hospital systems). Practices 2, 3, 4, and 5 had a shared mental model for integration, meaning that they shared an understanding of the practice's vision and approach to integrating care for patients. This included a systematic approach to identifying patient need for 
Table 5. Shared mental model for integration and close proximity of BHC and PCCs shapes use of warm handoffs and REACH of integration program among a group of practices with similar characteristics

\begin{tabular}{|c|c|c|c|c|c|}
\hline Practice ID & 2 & 1 & 4 & 5 & 3 \\
\hline \multicolumn{6}{|l|}{ Practice Characteristics } \\
\hline $\mathrm{PC} / \mathrm{MH}$ & $\mathrm{PC} / \mathrm{MH}$ & PC/MH & $\mathrm{PC}$ & $\mathrm{PC}$ & $\mathrm{PC} / \mathrm{MH}$ \\
\hline Ownership & $\begin{array}{l}\text { Private, not for } \\
\text { profit }\end{array}$ & $\begin{array}{l}\text { Private, not for } \\
\text { profit }\end{array}$ & $\begin{array}{l}\text { Private, not for } \\
\text { profit }\end{array}$ & $\begin{array}{r}\text { Hospital } \\
\text { system }\end{array}$ & Private \\
\hline $\begin{array}{l}\text { Govt/FQHC/CMHC \& } \\
\text { FQHC/None }\end{array}$ & FQHC/CMHC & FQHC/CMHC & FQHC & None & Government \\
\hline \multicolumn{6}{|l|}{$\begin{array}{l}\text { Characteristics of the integration } \\
\text { model }\end{array}$} \\
\hline \multicolumn{6}{|l|}{$\begin{array}{l}\text { Breadth and depth of } \\
\text { Integration REACH }\end{array}$} \\
\hline Identification of problem & $\begin{array}{l}\text { Systematic } \\
\text { screening }\end{array}$ & $\begin{array}{l}\text { Systematic } \\
\text { screening }\end{array}$ & $\begin{array}{l}\text { Systematic } \\
\text { screening }\end{array}$ & $\begin{array}{l}\text { Systematic } \\
\text { screening }\end{array}$ & $\begin{array}{l}\text { Systematic } \\
\text { screening }\end{array}$ \\
\hline Provision of services & Broad & Limited & Broad & Broad & Broad \\
\hline \multicolumn{6}{|l|}{$\begin{array}{l}\text { Relevant workforce located in } \\
\text { practice }\end{array}$} \\
\hline $\begin{array}{l}\text { Embedded } \mathrm{BHC} \text { on PCC } \\
\text { team }\end{array}$ & Yes & No & Yes & Yes & Yes \\
\hline $\begin{array}{l}\text { Consulting psychiatrist in } \\
\text { practice }\end{array}$ & Yes & Yes & No & Yes & Yes \\
\hline \multicolumn{6}{|l|}{$\begin{array}{l}\text { Approach to transitioning } \\
\text { patients to } \mathrm{BHC}\end{array}$} \\
\hline Warm-handoff & $X$ & & $\mathrm{X}$ & $\mathrm{X}$ & $\mathrm{X}$ \\
\hline Referral & $X$ & $\mathbf{X}$ & & & \\
\hline \multicolumn{6}{|l|}{$\begin{array}{l}\text { Path identified for other } \\
\text { services }\end{array}$} \\
\hline Specialty MH & Referral & Referral & Referral & Referral & Referred \\
\hline Substance Use & $\begin{array}{l}\text { Warm-handoff and } \\
\text { referral }\end{array}$ & Referral & Referral & Referral & Referral \\
\hline $\begin{array}{l}\text { Shared Mental Model for } \\
\text { Integration }\end{array}$ & Yes & No & Yes & Yes & Yes \\
\hline
\end{tabular}

Abbreviations: BHC, behavioral health clinician; CMHC, community mental health center; FQHC, federally qualified health center; FTE, full-time equivalent; $\mathrm{MH}$, mental health; PC, primary care; PCC, primary care clinician.

The designation of Government for ownership or financial characteristics indicated a non-FQHC- or CMHC-funded health system where the majority of financing or ownership is from the U.S. government.

The bold values listed for Practice 1 are to indicate how constructs such as physical distance among professionals and lack of a shared mental model can influence the approach to integrated care, despite practice characteristics that support broader integration approaches in other settings.

integration, brief, problem-focused therapy offered in the practice, adequate resources to establish clear pathways for patients with specialty mental health and substance use needs, and BHCs embedded on PCCs teams. Importantly, BHCs and PCCs were also located in close proximity to each other and routinely engaged in warm handoffs in these practices. ${ }^{26}$ This constellation of constructs led to a broad reach of integrated services among the patient population. In contrast, practice 1 (also shown in Table 5) did not engage in warm handoffs between primary care and behavioral health, and a referral approach emerged. Constructs that intertwined to contribute to this integration approach included PCCs and BHCs separated by physical distance (ie, on different floors of the building), misalignment among practice members on how best to deliver integrated care despite leadership's vision for more collaboration among PCCs and $\mathrm{BHCs}$, and BHCs who were more comfortable in a traditional therapeutic model. It is important to note that this practice employed systematic screening, but the integration program did not have broad reach because of these issues.

\section{Integration of Primary Care in Community Mental Health Centers}

The organizing constructs described above also apply to CMHCs that are colocating a primary care team. In addition, we found that CMHCs, particularly 
Figure 1. A case study demonstrating how the five organizing constructs intertwine to shape a practice's integration approach.

This is a small primary care practice located in a rural part of the state motivated to integrated behavioral health and primary care. They worked with a local community mental health center to locate a BHC to work in the practice part time. Although the practice is small, they repurposed a break room for the $\mathrm{BHC}$ to see patients. The $\mathrm{BHC}$ worked part-time partly because this was what the practice could afford, and partly because this was what the BHC wanted. The BHC was a local traditionally trained psychologist and had been working in the community, but this person had no prior experience integrating behavioral health and primary care.

The practice started by identifying a range of screening questions to use to identify patient need including identifying depression, anxiety, trauma, and substance use/abuse. Brief questions were added to the questions that patients received from the front desk staff upon check-in and completed in the waiting room about their medical conditions; the MA reviewed these items with patients when s/he brought them to the examination room. Once these questions were identified and added to the existing patient screening protocol, they were routinely and consistently completed. The practice learned that many of the practice's patients needed integrated care.

Unfortunately, the BHC was in the practice only a few days a week (.7 FTE), and preferred to deliver traditional therapy to patients. In addition, the practice had not clearly defined the patients they could care for in the practice or those needing to be referred to outside resources for more specialize longer-term treatment. While the practice has many medical specialists for referrals, they had not established the same pathways for mental health. The BHC's schedule was filled, almost immediately, with patients in need of long-term traditional therapy, making the $\mathrm{BHC}$ unavailable to the PC team and to the majority of patients this practice served.

This frustrated the PCCs. They recruited a new BHC who had prior experience working in integrated primary care. During this provider's first weeks in the practice, s/he shadowed the PCCs and moved their work desk into the PCC's office space. During this process s/he learned that the PCCs did not know how best to triage patients; how to determine which patients could be treated in an integrated behavioral health-primary care model, and which patients had needs that would be better addressed by outside organizations providing specialized mental health and substance use services. The $\mathrm{BHC}$ recognized s/he needed to do some retraining, and needed to rebuild relationships and care pathways with organizations in the community. This BHC knew s/he would also get bogged down doing traditional therapy if triaging was not addressed and clear pathways for patients needing longer-term therapy were not established.

those trying to redefine their organization's identity to one serving a community of patients with a range of integrated health care needs, not just serious and persistent mental illness, needed to consider how to care for patients with specialized medical needs, for patients with mild to moderate emotional and behavioral needs, as this had not previously been the focus of their practice, and needed to establish how PCCs and traditional mental health professionals would collaborate in this newly envisioned organization. Interestingly, 1 practice transitioned a mental health clinician to function as an embedded BHC consultant on the newly embedded primary care team.

\section{Interdependencies among Constructs and Contextual Factors}

The constructs we identified are highly interdependent, and the ways in which they intertwine shape practices' approach to integration. How these constructs come together is influenced by the context in which an organization is embedded (eg, state based policies, payment). Figure 1 presents an illustrative case study showing how, when appropriate identification of patient need and triaging did not happen, BHCs' accessibility to the primary care team is reduced. In this case study, this was a self-reinforcing cycle. PCCs did not know how to 
triage patients, the practice had not established care pathways for patients with longer-term behavioral health needs, and the BHC was traditionally trained with a preference for engaging patients in traditional therapy, and an inability to establish triage strategies and care pathways. Thus, although this practice aspired to fully integrate care for all practice patients, the result was a colocated, referral approach with capacity to systematically screen patients to identify need but a limited capacity to meet the needs of patients for integrated care.

\section{Discussion}

Through careful observation of diverse practices in diverse settings, we found 5 organizing constructs underlying varying integration approaches. These 5 organizing constructs-integration reach, development of care pathways, approach to care transitions, location of integration workforce, and shared mental model for integration-intertwined with practice context to produce the integration approaches we observed in real-world practices across the United States, and had implications for delivery of patient care in these settings.

Contextual factors, particularly practice type (eg, FQHC, CMHC), influenced whether specialty mental health and substance use services were colocated within an organization. FQHCCMHC hybrids had these services colocated within their building, integrated and hospitalowned health systems often had these service colocated within their facility or campus, and FQHCs and independent practices tended to connect with external community resources to access these services for their patients. Our findings show that practices that colocated the full spectrum of behavioral health resources and used warm handoffs to transition patients to embedded behavioral health relied on referrals for specialty mental health needs.

The practices we studied did not fit neatly into the integration model typology (ie, coordination, colocation, integration) that has been central to shaping this field. ${ }^{27-29}$ Care pathways and, in particular, whether practices used warm handoff or referral approaches, are a good example because practices could use both for good reason and to good effect. As more practices move toward integrating care, there is likely to be an increasing need to migrate away from some existing heuristics (eg, levels, models), ${ }^{27-29}$ and sharpen the focus on the particulars in practices' approaches to integration. Models have tremendous relevance in identifying common conceptual elements or behaviors, and these have led to standardizations critical for unifying the field of integration. Yet, these conceptual and definitional frameworks, such as those the AHRQ Lexicon ${ }^{23}$ that maintain consistency through definition, cannot be expected to mirror the many nuances emerging among practices integrating care in real-world settings. Our study, because it is grounded in the reality of practice, identifies constructs that complement and extend these frameworks by capturing some of the dynamic forces shaping integration efforts. Rather than offering a prescriptive model organization leaders and change agents attempt to abide by, the constructs identified are relevant to different types of practice settings and represent an organic set of issues that can be, and must be, addressed as practices configure and mature their integration approaches.

We identified integration reach, that is, the approach a practice used to identify and meet patient need, as an organizing construct. This construct, and the approaches we saw employed to identify patient need (ie, systematic screening, clinician discretion) has generated much dissent in the research and practice communities. ${ }^{30}$ To add to this dialog, we suggest that there are pros and cons that must be carefully weighed by organization leaders about how best to identify patient needs. Systematic screening, even if patient need was not immediately met, allowed practices to learn the needs of the population served, and some practices found motivation in this knowledge, working to develop the infrastructure to best serve their patients. Clinical discretion did not provide this information and possible motivation, but was a useful way to manage resources and a temporary way to work out the organization's integration approach without getting overwhelmed by the large number of screen positives that might result from systematic screening approaches.

We studied a purposefully selected group of practices motivated to integrate care. This is a study strength because we could not have examined the organization of integration among unmotivated practices not integrating care; it is a limitation given that these practices could be different from less-motivated practices. By establishing a maximum variation sample that widely represented U.S. 
practices on key attributes, we mitigated this limitation to the extent possible, but the findings apply most closely and relevantly to practices attempting to integrate care. In addition, although we reached saturation in this analysis, it is possible that there are other organizing constructs than those that manifest among our study sample. Having a relatively large and varied study sample gives us confidence that the organizing principles we identified are valid and transferrable. However, it is always possible that future studies will identify other important organizing constructs. The findings of this study could also be shaped by observer and classification biases. For example, we do not have quantitative estimates of REACH for some of the practices we studied, and our assessment is based on qualitative data sources. It is possible factors shaping researchers' preconceptions may have skewed our assessments. This limitation was mitigated by having multiple people in the field, not relying on a single person's assessment, with regard to REACH (or the other study findings), and having both quantitative and qualitative assessments among ACT practices to confirm the validity of our qualitative assessments. Finally, we do not present outcome data for these practices, and do not know the effectiveness of the services they provide. Future efforts should examine the outcomes of the integration approaches emerging in real-world practices.

\section{Conclusion}

As practices move toward solving the challenge of integrating primary care and behavioral health, policy makers, organizational and practice leaders, and researchers may find it useful to focus their work on these 5 organizing constructs simultaneously: integration REACH, development of care pathways, approach to care transitions, location of integration workforce, and a shared mental model for integration. These constructs are interdependent and intertwine with practice context to produce locally specific integration approaches that affect the care patients receive. Combined with paying attention to relevant contextual factors, they offer practical focal points for organizing and enabling practices to redesign for integrated care. For researchers, the organizing constructs provide an empirically derived framework of potential use in pragmatic trials and further work to develop practice-based evidence relevant to furthering integration efforts.

The authors are grateful to the participating practices and their patients. We thank Leah Baruch, MD, for her assistance with data collection on the IWS study and Claire Diener for her assistance formatting tables. The authors are also grateful for editing and publication assistance from Ms. LeNeva Spires, Publications Manager in the Department of Family Medicine at Oregon Health \& Science University.

\section{References}

1. Institute of Medicine. Crossing the quality chasm: A new health system for the 21 st century. Washington, DC: National Academy Press, 2001.

2. The Center for Consumer Information \& Insurance Oversight. Mental Health Parity and Addiction Equity Act (MHPAEA) 2008. http://cciio.cms.gov/ programs/protections/mhpaea/index.html. Accessed December 1, 2012.

3. Goodson JD. Patient Protection and Affordable Care Act: Promise and peril for primary care. Ann Intern Med. 2010;152(11):742-4.

4. Butler M, Kane RL, McAlpin D, et al. Integration of Mental Health/Substance Abuse and Primary Care No. 173 (Prepared by the Minnesota EvidenceBased Practice Center under Contract No. 290-020009.) AHRQ Publication No. 09-E003. Rockville, MD: Agency for Healthcare Research and Quality, October 2008.

5. Collins C, et al. Evolving Models of Behavioral Health Integration in Primary Care. Milbank Fund Report, 2010.

6. Miller BF, Petterson S, Brown Levey SM, PayneMurphy JC, Moore M, Bazemore A. Primary Care, Behavioral Health, Provider Colocation, and Rurality. J Am Board Fam Med 2014;27:367-74.

7. Croghan TW, Brown JD. Integrating mental health treatment into the patient-centered medical home (prepared by Mathematica Policy Research under contract No. HHSA290200900019I TO2). Rockville, MD: Agency for Healthcare Research and Quality, 2010.

8. Gallo JJ, Zubritsky C, Maxwell J, et al. Primary care clinicians evaluate integrated and referral models of behavioral health care for older adults: Results from a multisite effectiveness trial (PRISM-e). Ann Fam Med 2004;2:305-9.

9. Kwan B, Nease D Jr. The state of the evidence for integrated behavioral health in primary care. In: Talen MR, Burke Valeras A, eds. Integrated behavioral health in primary care: New York: Springer, 2013;65-98.

10. Peek CJ, Cohen DJ, deGruy FV 3rd. Research and evaluation in the transformation of primary care. Am Psychol 2014;69:430-42. 
11. Miller BF, Kessler R, Peek CJ, Kallenberg GA. A national agenda for research in collaborative care: Papers from the Collaborative Care Research Network Research Development conference. AHRQ publication No. 11-0067. Rockville, MD: Agency for Healthcare Research and Quality, July 2011.

12. Miller BF, Brown Levey SM, Payne-Murphy JC, Kwan BM. Outlining the scope of behavioral health practice in integrated primary care: Dispelling the Myth of the one-trick mental health pony. Fam Syst Health. 2014;32:338-44.

13. Stange KC. The paradox of the parts and the whole in understanding and improving general practice. Int J Qual Health Care 2002;14:267-8.

14. Berwick DM, Nolan TW, Whittington J. The Triple Aim: Care, health, and cost. Health Aff (Millwood) 2008;27:759-69.

15. Cohen DJ, Davis MM, Hall JD, Gilchrist EC, Miller BF. A guidebook of professional practices for behavioral health and primary care integration: Observations from exemplary sites. Rockville, MD: Agency for Healthcare Research and Quality, March 2015.

16. Davis M, Balasubramanian BA, Waller E, Miller BF, Green LA, Cohen DJ. Integrating behavioral and physical health care in the real world: Early lessons from advancing care together. J Am Board Fam Med 2013;26:588-602.

17. Glasgow RE, Vogt TM, Boles SM. Evaluating the public health impact of health promotion interventions: the RE-AIM framework. Am J Public Health 1999;89:1322-27.

18. Miller WL, Crabtree BF. The dance of interpretation. In: Crabtree BF, Miller WL, eds. Doing qualitative research. 2nd ed. Thousand Oaks, CA: Sage Publications, 1999;127-43.

19. Borkan J. Immersion/crystallization. 2nd ed. Thousand Oaks, CA: Sage Publications, 1999.

20. Peek CJ. Lexicon for behavioral health and primary care integration: Concepts and definitions developed by expert consensus. Rockville, MD: Agency for Healthcare Research and Quality. April, 2013. AHRQ Publication No. 13-IP001-EF.

21. Balasubramanian BA, Fernald D, Dickinson M, et al. REACH of interventions integrating primary care and behavioral health. J Am Board Fam Med 2015;28:S73-S85.

22. Cohen DJ, Davis M, Balasubramanian BA, et al. Integrating behavioral health and primary care: consulting, coordinating and collaborating among professionals. J Am Board Fam Med 2015;28:S21-S31.

23. Strosahl K. Building primary care behavioral health systems that work: A compass and a horizon. In: Cummings NA, Cummings JL, Johnson JN, eds. Behavioral health in primary care: A guide for clinical integration. Madison: Psychosocial Press, 1997; 37-58.

24. Strosahl K. The integration of primary care and behavioral health: Type II change in the era of managed care. In: Cummings NA, O'Donohue WT, Hayes S, Follette $\mathrm{V}$, eds. Integrated behavioral healthcare: Positioning mental health practice with medical/surgical practice. New York: Academic Press, 2001;45-70.

25. Strosahl K, Robinson P. The primary care behavioral health model: Applications to prevention, acute care and chronic condition management. In: Kessler R, Stafford D, eds. Collaborative medicine case studies: Evidence in practice. New York: Springer, 2008.

26. Gunn R, Davis M, Hall JD, et al. Designing clinical space for the delivery of integrated behavioral health and primary care. J Am Board Fam Med 2015;28: S52-S62.

27. Blount A. Integrated primary care: Organizing the evidence. Fam Syst Health 2003;21:121-33.

28. Collins C, Hewson DL, Munger R, Wade T. Evolving models of behavioral health integration in primary care. New York: Milbank Memorial Fund, 2010.

29. Peek CJ. Lexicon for behavioral health and primary care integration: Concepts and definitions developed by expert consensus. Publication No. 13-IP001-EF. Rockville, MD: Agency for Healthcare Research and Quality, 2013.

30. Kathol RG, Degruy F, Rollman BL. Value-based financially sustainable behavioral health components in patient-centered medical homes. Ann Fam Med 2014;12:172-5. 